\title{
Living in a return-to-play world: walking on thin ice
}

\author{
Johanna Ihalainen, ${ }^{1}$ Benjamin Waller (1) 2,3
}

\section{LIVING IN A RETURN-TO-PLAY WORLD: WALKING ON THIN ICE}

The beauty of Finland never fails to provide a wow factor as shown in the cover photo and figure 1. Stepping out onto a frozen lake creates uncertainty; you need to test the strength of the ice-will it hold? If the ice cracks, do you turn back or take a different route? As our cover picture shows, the trail across the ice does not follow a set path and never goes in a straight line. The path drawn in the snow and the uncertainty surrounding each step resemble the integrated return to sport pathway. ${ }^{1}$ One year ago, the warm-up of British Journal of Sports Medicine (BJSM) was about COVID-19 restrictions, and today, we are still being affected by lockdowns and sickness related to COVID19. ${ }^{2}$ More than ever, return-to-play (RTP) protocols and structures are needed.

\section{BEWARE THE DANGERS THAT LIE BENEATH}

Walking on thin ice reflects RTP on many levels. Different trails of footprints start and stop at the same point, but all take a different route to reach their destination. Even when the ice looks thick and someone else has already walked over it, there are no guarantees, your next step will be successful; instead, it may require a hasty retreat. Similarly, even when following the Strategic Assessment of Risk and Risk Tolerance $(\text { StARRT) })^{3}$ framework and using shared decision-making (SDM), ${ }^{4}$ RTP is always a case of weighing risks and benefits and may not always be successful. ${ }^{5}$

\section{THIS BJSM EDITION FOCUSES ON RTP}

Return to play is not one size fits all, especially as all athletes are different. The editorials by Skrubbeltrang et al (see page

\footnotetext{
${ }^{1}$ Faculty of Sports and Health Sciences, University of Jyväskylä, Jyvaskyla, Finland

2Physical Activity, Physical Education, Sport and Health (PAPESH) Research Centre, Sports Science Department, School of Social Sciences, University of Reykjavik, Reykjavik, Iceland

${ }^{3}$ Finnish Sports Physiotherapy Association, Finland
}

Correspondence to Dr Benjamin Waller, Physical Activity, Physical Education, Sport and Health (PAPESH) Research Centre, Sports Science Department, School of Social Sciences, University of Reykjavik, Reykjavik, Iceland; benw@ru.is

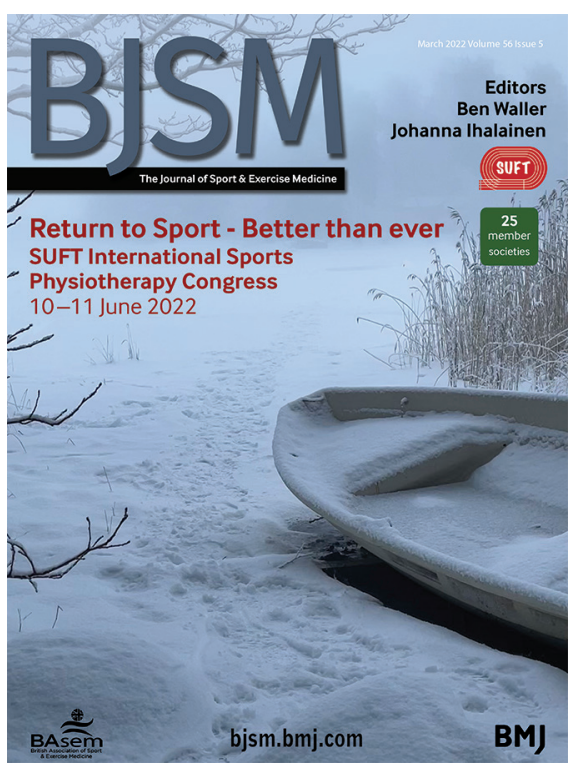

Figure 1 The beauty of a Finnish frozen lake-beware the dangers that lie beneath.

242) and Donnelly et al (see page 244) discuss RTP for young athletes and women postpartum, respectively. Both editorials indicate important areas where the sport and exercise medicine (SEM) practitioner can improve. The training limitations arising from injuries and illnesses present several psychological considerations that may influence RTP. These editorials also prioritise the athlete-centred approach. The editorial by Gledhull et al (see page 241) supports this and goes a step further by giving SEM practitioners some tools to assist athletes in gaining control during the RTP process and SDM interaction.

Current discussions on athlete health cannot avoid the topic of long-COVID and the clear difference between recovering from a 'typical' respiratory infection ${ }^{6}$ versus COVID-19.7 The vast numbers of athletes (and active people) affected by COVID-19 makes understanding an appropriate RTP pathway essential, however, there are many unknowns, and much research is still needed. The papers in this edition by Douryang et al (see page 246) and D'Ascenzi et al (see page 264) discuss different aspects of RTP following COVID-19 infection. Currently, we are stepping out on the thin ice, testing if it will hold, and determining which path we can use to make it safely to the other side. The ice may have cracks, it might break, and we may have to return to the start.

\section{SUFT CONGRESS 2022, JUNE 10-11} 2022: RETURN TO PLAY: BETTER THAN EVER

We wrote in 2021 that 2020 was not a great year for congress organisers. It turns out 2021 was not much better. Like other organisations, the Finnish sports Physiotherapy Association (SUFT) replaced its congress 'The athlete's pain' with a successful series of webinars.

A congress is not just about the content but also about the interactions that happen around the schedule and during the free time. Congresses are the one time of the year when friends and colleagues all meet in one place. The best example of this kind of recent congress was the IOC World Conference in Monaco in November, which was the best congress ever for both content and timing. Therefore, in 2022, SUFT is determined to hold our yearly congress on 10-11 June 2022 in Helsinki, Finland. The theme of the congress is 'Return-to-play: Better than ever'. The congress will focus on implementation of current knowledge into clinical practice and will cover the process from injury or illness onset to building robustness for optimal RTP. There will be a focus on athlete-centred decision-making, safeguarding during the RTP process, and examining the RTP process, from the athletes' perspective especially when better-than-ever does not mean in terms of sport performance but athletes' overall well-being and future.

We are proud to announce an amazing line up of speakers, including Dr Clare Ardern, Professor Evert Verhagen, Jo Gibson (MSc), Dr Phil Glasgow and Dr Nicol Van Dyk. Check out the congress pages for latest news and programme updates https://suftfi/ suft-kongressi/. See you all in Helsinki for a celebration of sports physiotherapy.

Twitter Johanna Ihalainen @jokasten and Benjamin Waller@BenWaller78

Contributors BW and $\mathrm{Jl}$ agreed the concept and wrote the content.

Funding The authors have not declared a specific grant for this research from any funding agency in the public, commercial or not-for-profit sectors.

Competing interests None declared.

Patient consent for publication Not applicable.

Ethics approval This study does not involve human participants.

Provenance and peer review Commissioned; internally peer reviewed.

(c) Author(s) (or their employer(s)) 2022. No commercial re-use. See rights and permissions. Published by BMJ. 


\section{Check for updates}

To cite Ihalainen J, Waller B. Br J Sports Med 2022;56:239-240.

Accepted 26 January 2022

Br J Sports Med 2022:56:239-240.

doi:10.1136/bjsports-2022-105485

ORCID iD

Benjamin Waller http://orcid.org/0000-0002-07380670

\section{REFERENCES}

1 Ardern CL, Glasgow P, Schneiders A, et al. 2016 consensus statement on return to sport from the first world Congress in sports physical therapy, Bern. $\mathrm{Br} J$ Sports Med 2016;50:853-64.

2 Waller B, Pasanen K. Drowning in a tsunami of online resources? time to take stock and re-invent. Br I Sports Med 2021;55:71-2.

3 Shrier I. Strategic Assessment of Risk and Risk Tolerance (StARRT) framework for return-to-play, 2015: 1311-5.

4 Dijkstra HP, Pollock N, Chakraverty R, et al. Return to play in elite sport: a shared decision-making process. $\mathrm{Br}$ J Sports Med 2017;51:419-20.
5 Lai $\mathrm{CCH}$, Ardern $\mathrm{CL}$, Feller JA, et al. Eighty-three per cent of elite athletes return to preinjury sport after anterior cruciate ligament reconstruction: a systematic review with meta-analysis of return to sport rates, graft rupture rates and performance outcomes. Br I Sports Med 2018;52:128-38

6 Snyders C, Pyne DB, Sewry N, et al. Acute respiratory illness and return to sport: a systematic review and meta-analysis by a subgroup of the $\mathrm{IOC}$ consensus on 'acute respiratory illness in the athlete'. Br I Sports Med 2022;56:223-31.

7 Hull JH, Wootten M, Moghal M, et al. Clinical patterns, recovery time and prolonged impact of COVID-19 illness in international athletes: the UK experience. $\mathrm{Br} / \mathrm{Sports}$ Med 2022;56:4-11. 